\title{
UNA APROXIMACIÓN AL DESARROLLO ECONÓMICO Y COMPETITIVO DE CHILE
}

\author{
Javier Leonardo Moreno Carrión \\ Facultad de Negocios, Gestión y Sostenibilidad \\ jlmorenoc@poligran.edu.co \\ Carlos Eduardo Gutiérrez Gómez \\ Facultad de Negocios, Gestión y Sostenibilidad \\ cegutierrezg@poligran.edu.co \\ William Andrés Huertas Murcia \\ Facultad de Negocios, Gestión y Sostenibilidad \\ Wahuertas1@poligran.edu.co
}

\section{Resumen}

El objetivo de este artículo es realizar una comparación de los principales indicadores macroeconómicos de Chile con las principales economías de la región. Luego, describir algunos factores como la institucionalidad, la gobernabilidad, la independencia de las instituciones financieras, las reformas tributarias, la competitividad y la apertura económica como piezas fundamentales para el crecimiento y desarrollo económico de Chile durante los últimos 30 años. En este sentido, las políticas fiscales, las reformas estructurales, la gestión de las metas inflacionarias, así como la generación de confianza y transparencia por parte del ejecutivo hacia el sector empresarial, han sido también fuente de crecimiento económico. Por último, se revisará los principales inconvenientes del modelo de desarrollo económico chileno, en donde se presentan los desafíos más grandes de este país en materia de desarrollo inclusivo, desigualdad, investigación y desarrollo y educación.

Palabras clave: Crecimiento económico, fuentes de crecimiento económico, competitividad, desarrollo inclusivo. 


\section{1ntroducción}

El presente artículo expondrá algunos aspectos que fueron cruciales para el crecimiento económico y desarrollo de Chile durante las últimas décadas, a partir de un proceso descriptivo en el cual se realizó un rastreo netamente bibliográfico. Se presentarán varios análisis de los principales indicadores macroeconómicos e índices de competitividad mundial, en comparación con las principales economías de la región. Por último, expondrá los nuevos retos que tiene Chile de frente a un futuro que plantea diferentes desafíos en materia de desigualdad, investigación y desarrollo (I+D) y desarrollo inclusivo. El escrito, está inspirado en la visita académica desarrollada en el mes de mayo del año 2018 a la ciudad de Santiago de Chile, en del desarrollo de la Especialización en Gestión Empresarial de la Institución Universitaria Politécnico Grancolombiano y en última medida, por la interesante evolución de la economía chilena. En ese sentido, es importante resaltar que en los últimos 30 años, el Producto Interno Bruto (PIB) de Chile ha crecido en promedio 4,9\% según estimaciones del Banco Central de Chile, registrando cuatro años de incremento neto entre 1990 y 1994, tiempo en el cual el promedio del PIB fue de 7,3\% (Wolrd Bank Group, 2018). El constante aumento del PIB en la década de los años 90 y otros aspectos - a tratar dentro de este documento- han llevado a que "Chile sea presentado, con frecuencia, como un caso paradigmático de reformas y crecimiento exitoso" (Ffrench Davis, 2016,p.6).

Partiendo de esta consideración, el crecimiento económico de chile durante los primeros años de los gobiernos de la concertación fue en efecto admirable para una nación que venía de turbulencias sociales y marcada por el fin de la dictadura militar en la cual el crecimiento del PIB se situaba por el orden del 2.9\% entre 1973 y 1989 (Ffrench Davis, 2016). En efecto el regreso de la democracia introdujo un periodo de orden constitucional, garantizando la libertad individual ( Núñez Salazar, 2015), lo anterior, permitió grandes avances en el crecimiento con equidad, a tal punto, que la política de Chile a partir de 1990 tuvo como objetivo principal la disminución de la pobreza, la exclusión social y la desigualdad, de la mano de una economía que depositó sus procesos de distribución de recursos y crecimiento bajo el funcionamiento de los mercados y la iniciativa privada (Larrañaga \& Valenzuela, 2011). No obstante, el estancamiento en el crecimiento económico fue protagonista durante la primera y segunda década del siglo XXI, debido a que entre el año 2000 y 2010 la economía chilena creció en promedio $4,2 \%$ y lo que lleva de la segunda década el PIB en promedio fue de 3,2\% según estimaciones de datos del Banco Central de Chile. Entre las razones asociadas a dicho estancamiento la OCDE (2018) afirma que desde el año 2014 la caída de los precios del cobre y la debilidad en los mercados internacionales ha ralentizado el crecimiento.

\section{Fuentes de Crecimiento Económico}

Dentro de las múltiples causas relacionadas con el crecimiento económico en Chile, se pretende resaltar variables como la institucionalidad, la gobernabilidad, el marco de 
actuación del ejecutivo y el sector financiero, y la competitividad y la apertura económica como claves durante el proceso de crecimiento.

El modelo económico-político que Chile ha desarrollado en las últimas tres décadas le ha permitido consolidar sus instituciones básicas las cuales han aportado al crecimiento económico y han incrementado el progreso social y la estabilidad política (Saavedra, 2014). siendo la economía de más rápido crecimiento en la región (Wolrd Bank Group, 2018). En el Gráfico 1 se evidencia cómo ha sido el crecimiento del PIB para las principales economías de la región en los últimos 30 años, mostrando que, si bien el crecimiento de las economías latinoamericanas no ha sido sostenible en el tiempo, en el caso Chile, se observa una hegemonía para la década de 1990, ya para la primera década del nuevo siglo Chile y Colombia muestran un crecimiento leve con una fuerte caída del PIB producto de la crisis financiera del 2008. Aunque, la recuperación empezó en el 2010 el estancamiento del crecimiento desde el año 2014 no ha tenido repunte ubicando al crecimiento promedio en $2,2 \%$ hasta el 2017.

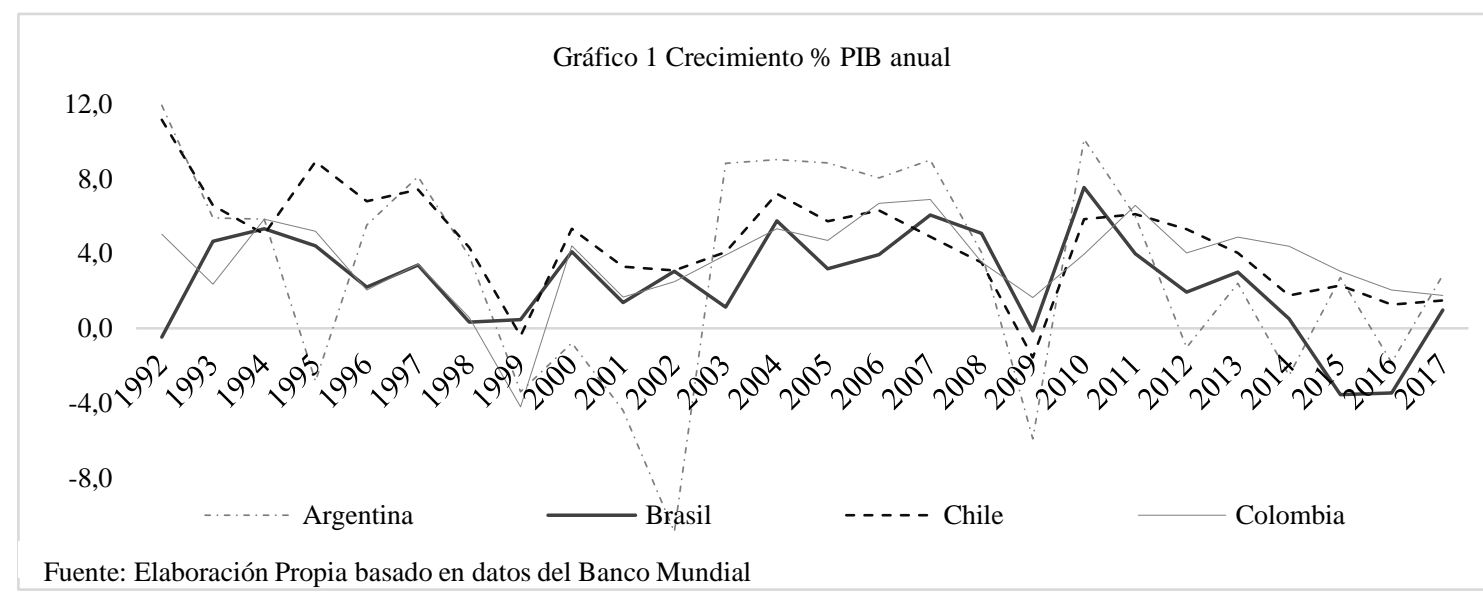

Grafica 1

La tabla 1 muestra el promedio de crecimiento del PIB en varios periodos de tiempo, concluyendo que Chile para el periodo entre 1992 y 1999 tuvo un promedio de 6,2\%, seguido de Argentina 4,4\% y Brasil y Colombia con 2,5\% respectivamente. Entre los periodos del 2000-2010 y 2011-2017 Chile fue la economía que más crecimiento tuvo con un promedio de $4.3 \%$ y $3,2 \%$ respectivamente, únicamente superado por Colombia en el periodo de 2011-2017 que tuvo un promedio de crecimiento del 3,8\%. Aun así, Chile sigue superando de nuevo a Argentina, Brasil y Colombia; si se toma todo el periodo desde 1992 hasta 2017 creciendo en promedio 4.6\%, sustancialmente mayor que el 3,6\% de Colombia y el 3,1\% de Argentina. 
Tabla 1 -. Promedio de crecimiento \% PIB anual

\begin{tabular}{c|ccc}
\hline País & $\begin{array}{c}\text { Promedio de } \\
\text { Crecimiento 1992- }\end{array}$ & $\begin{array}{c}\text { Promedio de } \\
\text { Crecimiento 2000- }\end{array}$ & $\begin{array}{c}\text { Promedio de } \\
\text { Crecimiento 2011- }\end{array}$ \\
Argentina & 1999 & 2010 & 2017 \\
Brasil & 4,4 & 3,3 & 1,2 \\
Chile & 2,5 & 3,7 & 0,5 \\
Colombia & 6,2 & 4,3 & 3,2 \\
\end{tabular}

Fuente: Elaboración propia basado en el Banco Mundial

En cuanto al PIB per cápita, en el Gráfico 2 se evidencia que Chile también figura protagonista en comparación con los demás países de América Latina y el Caribe. El promedio del PIB Per Cápita de Chile para 1994 fue de \$4.046, ya para el año 2014 era de $\$ 14.794$, es decir que Chile en 20 años logro incrementar su PIB Per Cápita en un 266\%, América Latina y del Caribe tuvo un incremento del 173\% en su PIB Per Cápita en el mismo periodo de tiempo, los resultados de Chile se explican en gran medida por las reformas que se han realizado durante los diferentes gobiernos (Saavedra, 2014).

\section{Inflación, un tema que ocupa al Banco Central.}

Una inflación elevada conlleva sobrecostos para cualquier economía, ya que produce imprecisiones en la distribución de recursos (De Gregorio, 2009). Lo anterior, se traduce en dificultades para la política monetaria y fiscal de cualquier país como lo fue durante el gobierno de Allende, periodo en el cual la inflación se desató ya que el déficit fiscal se podía financiar con la emisión de dinero, en gran parte por la dependencia del Banco Central al gobierno de turno (Saavedra, 2014).

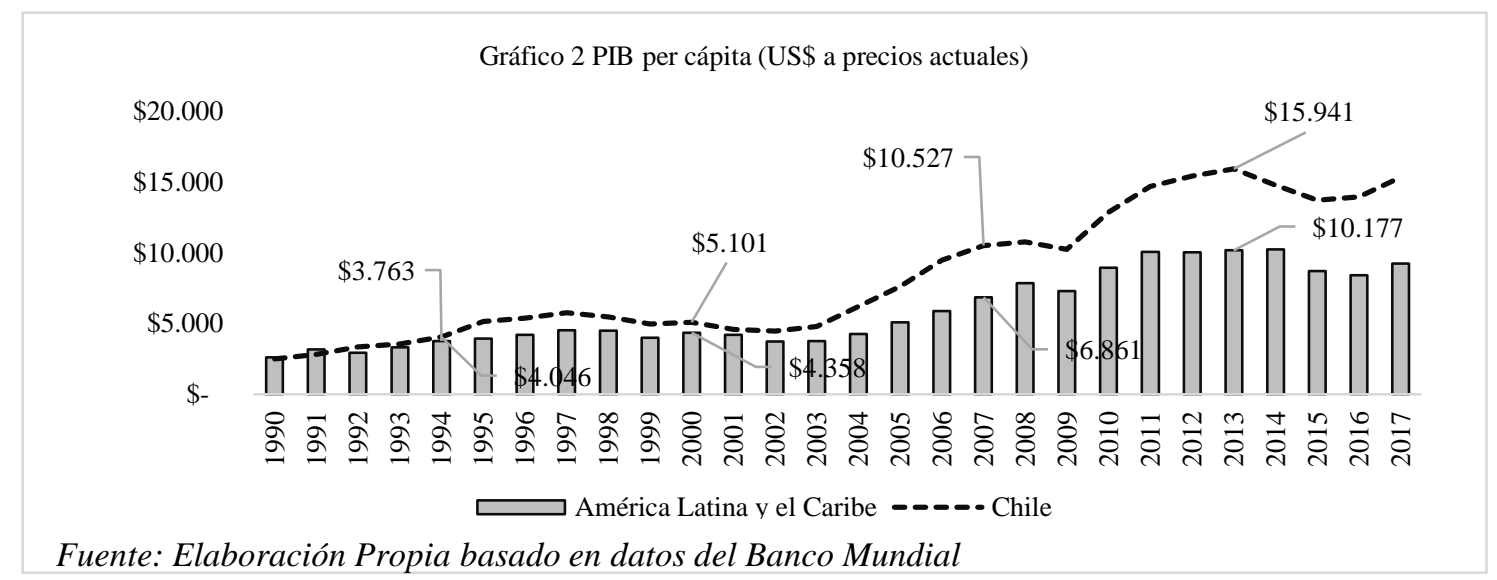

En efecto, la importancia de la independencia y autonomía del Banco Central de Chile en el manejo de la inflación - como se verá en otros aspectos más adelante- ha sido fundamental para mantener porcentajes promedio de inflación del 6,4\% desde 1990 a la fecha según estimaciones basadas en datos del Banco Mundial. Además, es crucial resaltar la prohibición que la Ley Orgánica de 1989 imparte, haciendo referencia a que 
ningún gasto público podrá financiarse con créditos directos o indirectos del Banco Central, (De Gregorio, 2009). Es decir, que el Banco Central deberá gestionar las metas inflacionarias de forma objetiva asegurando el sostenimiento del crecimiento económico, y evitando cumplir los caprichos del gobierno de turno, lo cual como se cita en GarcíaSolanes y Torrejón-Flores (2012); Mujica \& Saenz,( 2015) es un logro fundamental de la economía chilena y en particular del Banco Central de Chile ya que se ha obtenido una tasa de inflación efectiva anual del 3\%, lo anterior, es significativo si se tiene presente que a finales de los años 80 esta tasa era del 30\% anual. Adicional, como señala García - Solanes \& Torrejón - Flores, (2012) desde el año 2000 el Banco Central de Chile viene publicando informes de las previsiones de inflación de referencia, resaltando las dos características claves en las que se ha basado el sistema de metas inflacionarias: la consistencia de las finanzas públicas y la solvencia de los sistemas financieros.

En consideración de lo anterior, De Gregorio (2009) señala que el aumento de la independencia del Banco Central ha estado asociada a una reducción de la inflación y mayor crecimiento económico. Por otro lado, Saavedra (2014) también afirma que la credibilidad del Banco Central tiene efectos inmediatos en la competitividad de la nación, dando fuertes señales de independencia en los momentos en donde la inflación se ha elevado sobre las metas esperadas, en este escenario el Banco ha dejado claro que su objetivo principal es gestionar sus metas inflacionarias y no la política fiscal del gobierno.

En el Gráfico 3 se puede observar cómo ha sido el comportamiento de la inflación durante las últimas décadas evidenciado la buena gestión del Banco Central incluso en comparación con algunos países de la región.

Teniendo en cuenta las afirmaciones realizadas, se puede concluir que en su conjunto la marcada tendencia de crecimiento económico, el aumento del ingreso Per Cápita, y los niveles bajos de inflación, han logrado que la economía chilena se haya fortalecido desde la década de los 90 (Riveros Cornejo \& Báez Castillo, 2014). De hecho, el desarrollo económico también ha traído consigo mejor calidad de vida de la población y disminución de los índices de pobreza (Arenas de Mesa, 2016). Cabe resaltar también, que una de las principales fortalezas del modelo económico-político chileno y también una de las razones por las cuales Chile muestra un crecimiento superior es que a través de sus instituciones más básicas ha podido alcanzar niveles de desarrollo superiores a los de sus compañeros de patio (Saavedra, 2014). En línea con lo anterior, Saavedra (2014) también describe que:

Chile muestra altas fortalezas institucionales en lo económico y político, las que, unidas, han sido capaces de crear las condiciones para el crecimiento sostenido y la consecuente reducción de la pobreza, que ha bajado desde un 38,4\% el año 1990 a 14.4\% en el año 2011. (p.142) 
Teniendo en cuenta las consideraciones anteriores, en las próximas dos secciones se describirá el papel de las instituciones dentro del escenario económico y se brindará un panorama general de como la política fiscal, la institucionalidad y la gobernabilidad han sido fuente de crecimiento económico incrementando también el desarrollo social dentro de Chile.

\section{Institucionalidad y Gobernanza}

$\underline{\text { Reformas y Leyes, las claves para el crecimiento económico en materia legislativa. }}$

La estabilidad económica junto a la implementación de reformas estructurales de fondo en temas como la apertura económica y la internacionalización del comercio y el boom de los precios del cobre y otros recursos naturales han mejorado la calidad de vida de los chilenos (OCDE, 2018). En este sentido, la OCDE (2018) refiere alguna de las reformas y leyes más importantes llevadas a cabo en los últimos años:

Ley para el Fortalecimiento y Transparencia de la Democracia (N. 20.900 de 2016), la nueva Ley de Partidos Políticos (N. 20.915 de 2016), la Ley de Sanción de Pérdida del Cargo (N. ${ }^{\circ} 20.870$ de 2015), la Ley de Probidad en la Función Pública (N. 20.880 de 2016), la Ley de Autonomía Constitucional del Servicio Electoral (N. 20.860 de 2016), la Ley de Educación Cívica Obligatoria (N. ${ }^{\circ} 20.911$ de 2016), la Ley de Fortalecimiento de la Alta Dirección Pública (N. 20.955 de 2016), y la Ley que crea la nueva Comisión

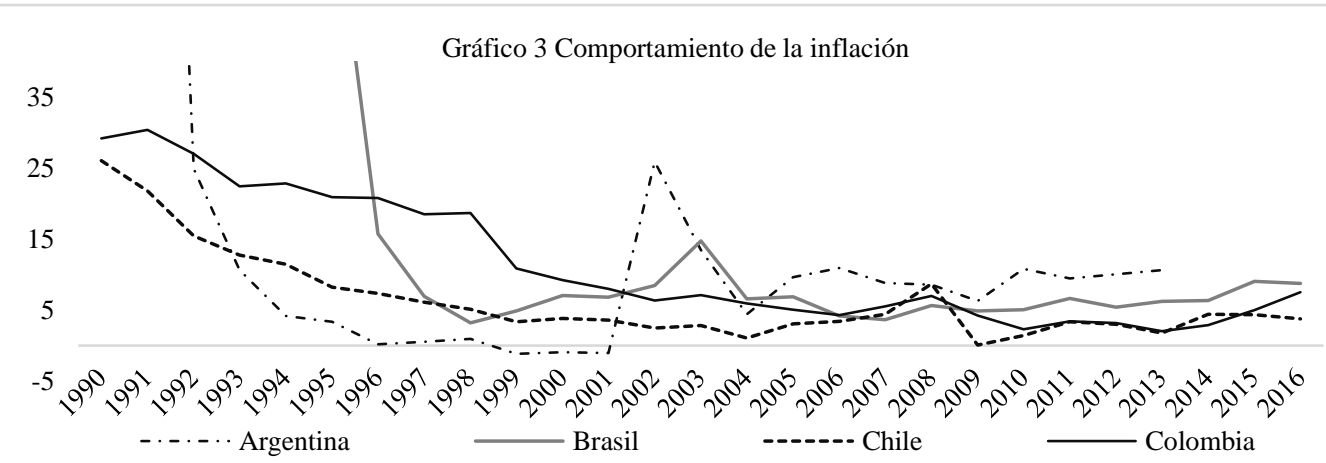

Fuente: Elaboración Propia basado en datos del Banco Mundial para el Mercado Financiero (CMF) (N. 21.000 de 2017).(p.248)

Por un lado se deduce que este paquete de leyes ha sido crucial para el desarrollo económico de Chile aumentando la confianza tanto del empresariado como de los agentes externos, resaltando temas como la transparencia y la democracia, regulación política y económica e inversión en educación, no obstante, es necesario nombrar otras reformas que a lo largo del tiempo han aportado significativamente a la credibilidad y confianza de las instituciones en Chile por su intervención en temas como la libre competencia, Saavedra (2018) explica, que se han dado tres reformas importantes en este tema, la primera en 1997 la cual otorgó mayores recursos y estructura a la Fiscalía 
Nacional Económica para que actuará de oficio en casos de conflicto de interés, en el 2004 se impuso el Tribunal de Defensa de la Libre Competencia con rango de Corte de apelaciones, este tribunal integrado por cinco miembros cuya elección de cuatro miembros está dada por el comité del Banco Central y el quinto por la Corte Suprema de Justicia, dando señales de transparencia e independencia, adicional, en el 2009 fue aprobada la nueva ley de Defensa de la Libre Competencia que en últimas concede nuevas atribuciones a la Fiscalía Nacional Económica y eleva las multas por sanciones, otras modificaciones importantes a esta ley se dieron en materia de derechos del consumidor en donde también se establecieron multas más altas y el derecho a las personas a demandar colectivamente a empresas que engañen masivamente a sus usuarios.

Otros avances se muestran en relación con la regulación financiera y bancaria, de hecho, en el año 2017 se incorporó la ley de Bancos con grandes aportes entre los que se resalta el marco jurídico que contempla la intervención temprana al sistema bancario y aumenta la gobernanza de los órganos de control (OCDE, 2018). En este sentido para evitar la difusión del riesgo sistémico de los conglomerados financieros, la regulación dicta al detalle la estructura de los bancos comerciales, separándolos de los bancos de inversión, prohibiendo que tengan acciones de empresas productivas (Saavedra, 2014). En efecto, Chile ha asumido políticas y leyes que apuntan a fortalecer su transparencia, tales como, la ley de transparencia aprobada en 2014 que obliga a hacer pública la información entre las relaciones de los funcionarios públicos con el sector privado (OCDE, 2018). también como veremos en el próximo punto, este ha sido un factor clave que le aporta a la creación de confianza empresarial social en el gobierno.

Gobernabilidad, Chile un país responsable.

En los últimos 20 años el proceso político chileno se ha identificado por desarrollar un esquema modernizado para prolongar el modelo de desarrollo económico y una lógica transicional proveniente de los años 80 (Mella Polanco \& Berrios Silva, 2013), comprometiéndose con el desarrollo de políticas que fortalezcan la confianza y transparencia (OCDE, CAF, \& CEPAL, 2018). y los indicadores lo demuestran, incluso por encima de sus pares regionales, por ejemplo, el índice de percepción de la corrupción de 2017, elaborado por Transparency International, (entre 100 (percepción de ausencia de corrupción) y 0 (percepción de muy corrupto) (Transparency International, 2017). ubica al país en la posición 26 dentro de 180 naciones con un puntaje de 67, Argentina ocupa el puesto 85 con una puntuación de 39 y Brasil y Colombia comparten la posición 96 con un puntaje de 32. La OCDE, CAF, \& CEPAL (2018), afirman que en indicadores de corrupción, calidad de la burocracia, ley y orden, América Latina obtiene un puntaje de 0.44 y la OCDE de 0.78 , Chile por su parte supera a América Latina y se mantiene justo debajo del promedio de la OCDE obteniendo un puntaje de 0.75. Adiconal, la OCDE,CAF\&CEPAL (2018) también indican que: "Según el Índice de Políticas Anticorrupción (que va de 0 a 10), Chile registra 9.0, por encima de los promedios de América Latina y el Caribe y la OCDE, de 5.12 y 6.91 respectivamente"(p.248).Por otro 
lado, los indicadores Mundiales de Gobernabilidad del Banco Mundial para el año 2016 permiten identificar seis indicadores agregados que se basan en más de 30 fuentes de datos subyacentes que informan las percepciones de la gobernanza de un gran número de encuestados y evaluaciones de expertos en todo el mundo (Wolrd Bank, 2017). para el indicador voz y responsabilidad ((oscila entre aproximadamente -2.5 (débil) a 2.5 (fuerte) desempeño de gobierno) Chile recibe una puntuación de 1 , mientras que Argentina obtiene 0,54.,Brasil 0,47 y Colombia 0,10; para el indicador estabilidad política - no violencia, Chile recibe la mejor calificación de las 4 economías obteniendo un 0,51 , le sigue Argentina con 0,22, Brasil en números rojos con - 0,45 y Colombia en el último lugar con -0,96; en el indicador eficacia del gobierno, de nuestro especial interés en esta parte del contenido, Chile obtiene un calificación de 1,02, seguido de Argentina con 0,18, Colombia con 0,02 y en último lugar Brasil con -0,18; para el indicador de control de la corrupción Chile nuevamente supera a sus pares regionales con una puntuación de 1,11; en el indicador llamado calidad regulatoria Chile sobresale con un puntaje de 1,1; y para el último indicador denominado imperio de la ley que refleja las percepciones de hasta qué punto los agentes confían y respetan las reglas de la sociedad y, en particular, la calidad de la ejecución de los contratos, los derechos de propiedad, la policía y los tribunales, así como la probabilidad de delincuencia y violencia (Wolrd Bank, 2017). Chile sigue manteniendo ventaja de las demás economías de su región con una puntuación de 1,13 .

En su totalidad, este grupo de indicadores y en general la lectura que hacen los agentes externos ya citados en este documento, indican que Chile es una de las economías que mejor está en materia de Gobernabilidad e Institucionalidad y que sin duda este aspecto si bien es cierto no es una fuente de crecimiento en sí mismo, si puede apalancar y generar nuevas fuentes de crecimiento de la economía.

Independencia y Autonomía de las Instituciones, el caso del Banco Central de Chile

En paralelo a lo anteriormente desarrollado, otro aspecto de relevancia como lo indica De Gregorio (2009) y que en últimas significó un cambio trascendental en la economía chilena es la independencia de algunas instituciones financieras, como el Banco Central de Chile, el cual tiene autonomía en su presupuesto, objetivos e instrumentos, y cuyo origen se da en la Constitución de 1989 bajo la Ley Orgánica Constitucional representando un éxito dada su consolidación y resultados en el tiempo, que llevaron como lo indica García - Solanes \& Torrejón - Flores, (2012) a una disminución gradual de la inflación.

La autonomía de las instituciones regulatorias financieras y la independencia del ejecutivo de los órganos de control no sólo aporta al equilibrio de poderes necesario en toda democracia, sino, que también da un parte de confianza al mercado dando un mensaje claro de evitar los caprichos del gobierno de turno en cuanto a política económica se refiere, siempre poniendo por encima la sostenibilidad económica. Estos cambios en la independencia de las instituciones fueron muy en línea con la tendencia 
de los años 90 en donde muchos gobiernos introdujeron dentro de sus reformas aspectos a favor de la independencia y autonomía de los bancos centrales (De Gregorio, 2009).

\section{Importancia de las Reformas Tributarias en el crecimiento económico}

El crecimiento económico también ha venido acompañado de la implementación de políticas sociales a través de componentes de inversión social y educacional, sin embargo, en ese sentido se presenta un desafío que los gobiernos han ligado estrechamente con la responsabilidad de la política fiscal que debe asegurar un ingreso permanente de financiación del gasto público y educativo, ejemplo de ello es la reforma previsional presentada en 2008 por el Gobierno de Michel Bachelet fijando políticas fiscales enfocadas en establecer fuentes de ingresos constantes para el gasto social pero desde un enfoque de sostenibilidad fiscal, partiendo del ideario de que las reformas estructurales son posibles cuando se financian de forma sostenible; al mismo tiempo los esfuerzos de las políticas sociales se han centrado en la disminución de la desigualdad y pobreza lo que ha demandado mayor demanda de recursos públicos (Arenas de Mesa, 2016).

En este sentido, es necesario un compromiso por parte del ejecutivo en apuntar a sostener el gasto fiscal en el tiempo, lo que implica reformas que aseguren un ingreso a las arcas del gobierno lo que en ultimas se termina traduciendo en reformas tributarias. Durante los últimos 30 años, han existido dos reformas tributarias que han tenido especial impacto en el crecimiento económico y política social; por un lado, en los años 90 Chile se enfrentaba a el reto de alcanzar un crecimiento sostenido y constante y en paralelo combatir la pobreza y desigualdad generada en el periodo de la dictadura militar (Ffrench Davis, 2016). Como consecuencia, la reforma tributaria de 1990 fue propuesta por el ejecutivo en 1989, y tuvo como objetivo estabilizar el sistema a económico y político con fines democráticos y financiar el programa de políticas sociales. Para esto, era necesario mostrar que un incremento en el recaudo fiscal era fundamental para la disciplina fiscal, lo anterior a partir de la creciente demanda de recursos por parte del ejecutivo en el nuevo periodo de la democratización (Fairfield, 2015). Teniendo en cuenta lo anterior, Arenas de Mesa (2016) expone los principales logros de esta reforma:

El financiamiento de un aumento sostenido del gasto público social, que acumuló un crecimiento del 38,2\% entre 1990 y 1994 (...); ii) el aumento de la carga tributaria del impuesto a la renta (equidad tributaria), y iii) el precedente de que los gastos permanentes deben ser financiados con ingresos permanentes. (p.167)

Adicional a lo descrito, también "se implementaron cambios sustanciales en las políticas fiscales, monetarias, cambiarias y regulatorias -con un fuerte sentido contra cíclico -que apuntaron a conseguir un entorno macroeconómico real, estable y sostenible, 
considerado por la autoridad como indispensable para el desarrollo económico" (Ffrench Davis, 2016,p12).

Entrando en la segunda década del siglo XXI se hizo necesario un ajuste a la reforma de 1990, "Las demandas estudiantiles de una gran reforma educativa no solo crearon una enorme necesidad de nuevos ingresos fiscales, sino que los estudiantes también exigieron explícitamente que el gobierno financiara la reforma con impuestos progresivos" (Fairfield, 2015). En consecuencia, en el 2014 el ejecutivo presento un nuevo proyecto de reforma tributaria con el objetivo de incrementar sus esfuerzos en relación con la desigualdad por medio del aumento en el financiamiento de programas de protección social, financiar en forma responsable la reforma educacional y aumentar los programas de ahorro e inversión con el fin de aportar a un Chile más inclusivo (Arenas de Mesa, 2016). La aprobación de la reforma significó el aumento de la financiación para las políticas sociales y para la reforma a la educación (OCDE, 2018).

Partiendo de la idea de que el gasto público por parte del estado puede ayudar a bajar las tasas de pobreza, desigualdad y desempleo, en el Gráfico 4 se presenta el gasto (\% del PIB) con la tasa de desempleo desde 1990 hasta el año 2016. Tras las subidas en 1999 y 2009 de la tasa de desempleo, el gasto público presenta el mismo comportamiento tratando de recortar los efectos negativos del aumento de la tasa de desempleo y otras repercusiones negativas producto de las crisis económicas vividas en estos dos periodos de tiempo.

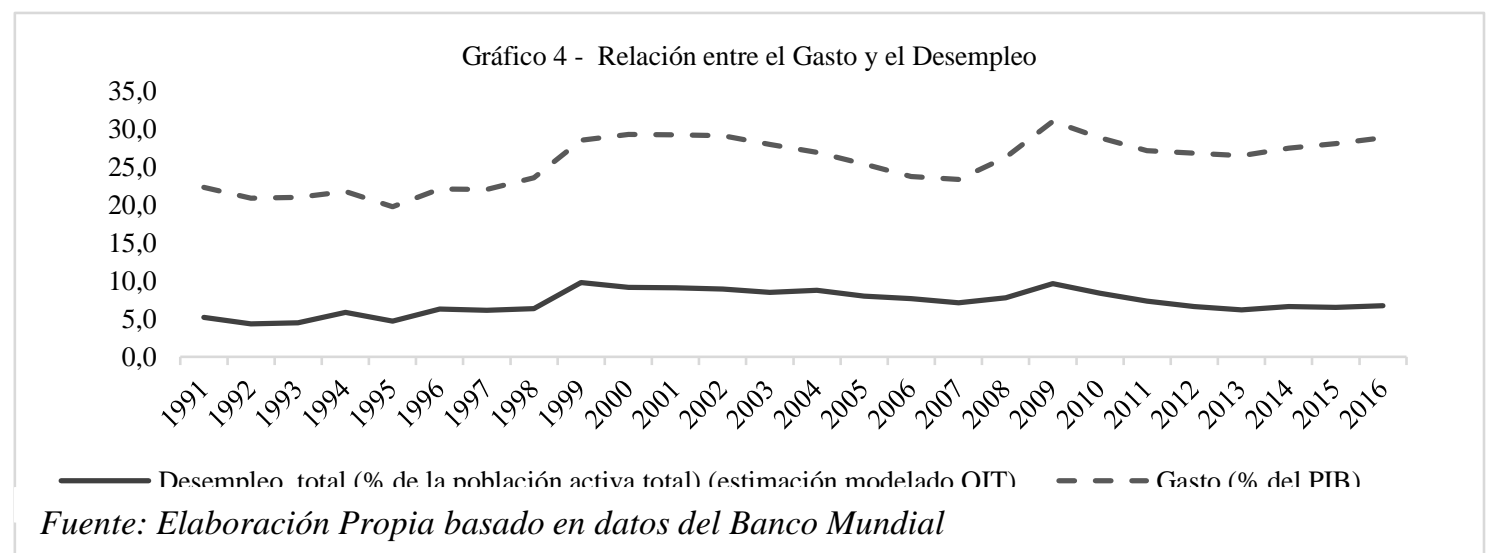

La Pobreza también continúo disminuyendo a pesar de que en los periodos mencionados (1999 y 2008) el desempleo presentó un aumento, lo cual, según Espinoza, , Barozet, \& Méndez (2013) "debe considerarse una indicación de la contribución del gasto público en este aspecto" (p.174). Por otro lado, Saavedra (2014) afirma que la política social acrecentada a partir de la década de 1990, paralelo al relevante crecimiento económico de Chile en los últimos 25 años permitió disminuir la tasa de pobreza desde un 38,4\% en 
1990 a un $14,4 \%$ en 2011. Así mismo, la tasa de extrema pobreza se decremento significativamente desde un $12,8 \%$ a un $2,8 \%$ en el mismo período.

En el Gráfico 5 se presenta la variable desempleo comparando a Chile con sus pares regionales, a primera vista saltan los resultados de la economía chilena siendo la única capaz de mantener tasas inferiores al 10\% desde 1991 hasta la fecha, muy compatible con las tasas de desempleo que presenta América Latina y el Caribe. Cabe mencionar que terminando la década de 1990 y entrando la década del 2000 se presentó un aumento generalizado del desempleo en el cual se ven castigados Colombia y Argentina con tasas superiores al 12\%, llegando inclusive en 1999 para el caso de Colombia a ubicarse en el $20 \%$.

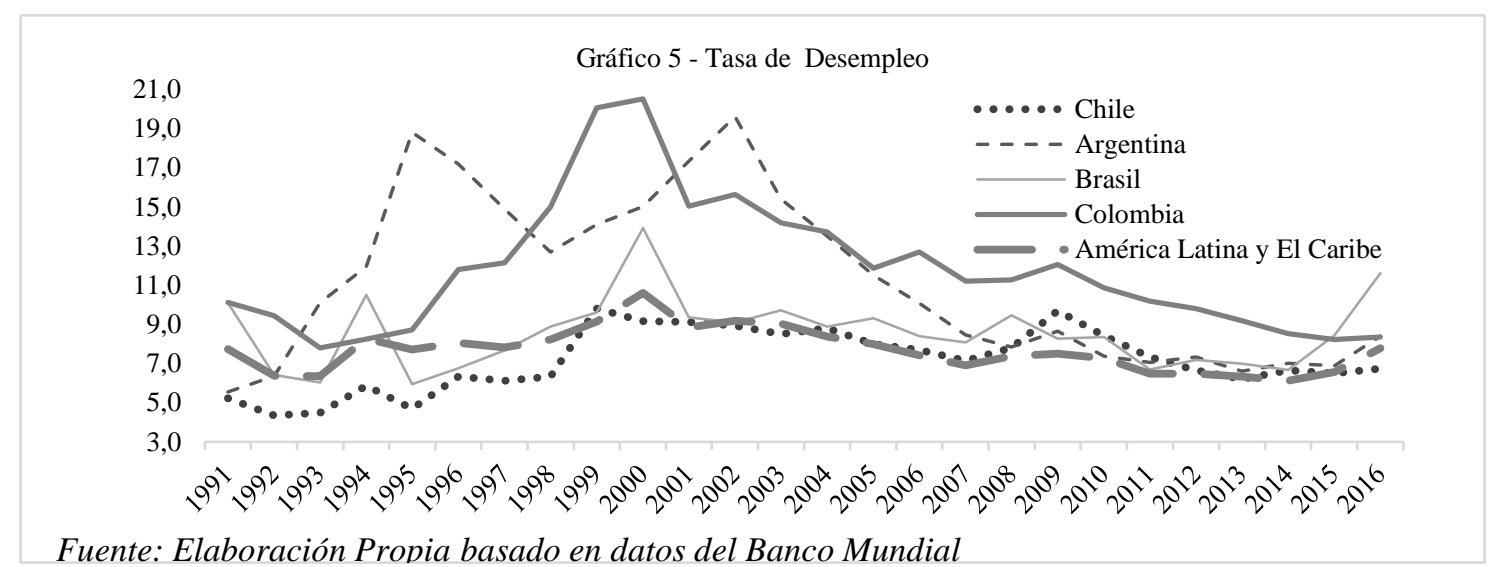

$\mathrm{Si}$ revisamos lo expuesto, en conjunto con los indicadores macroeconómicos presentados, es posible deducir que la economía chilena cuenta con reglas de juego claras, cuyo cumplimiento y eficacia de los gobiernos generan confianzas en los inversionistas. Todo ello ha rendido frutos en términos de un sostenido crecimiento económico (Saavedra, 2014).

\section{Competitividad}

La competitividad de la economía es la capacidad para competir en los mercados internacionales logrando una base importante en materia de estabilidad macroeconómica, siendo una economía atractiva a la inversión extranjera directa (Riveros Cornejo \& Báez Castillo, 2014).

De acuerdo con los datos de la Inversión Extranjera Directa Neta de Capital del Banco Mundial, Chile sólo es superado por Brasil, (Ver Gráfico 6), el promedio de la Inversión Extranjera Directa en el Capital Neto en Chile desde 1990 a la fecha es de \$9.664.973.905, considerablemente mayor a los \$7.104.245.266 de Argentina y los $\$ 6.538 .712 .170$ de Colombia. Se puede observar un aumento generalizado en la región 
de la inversión extranjera directa desde el año 2004 la cual, se ha sostenido hasta el año 2012 cayendo en una tendencia a la baja.

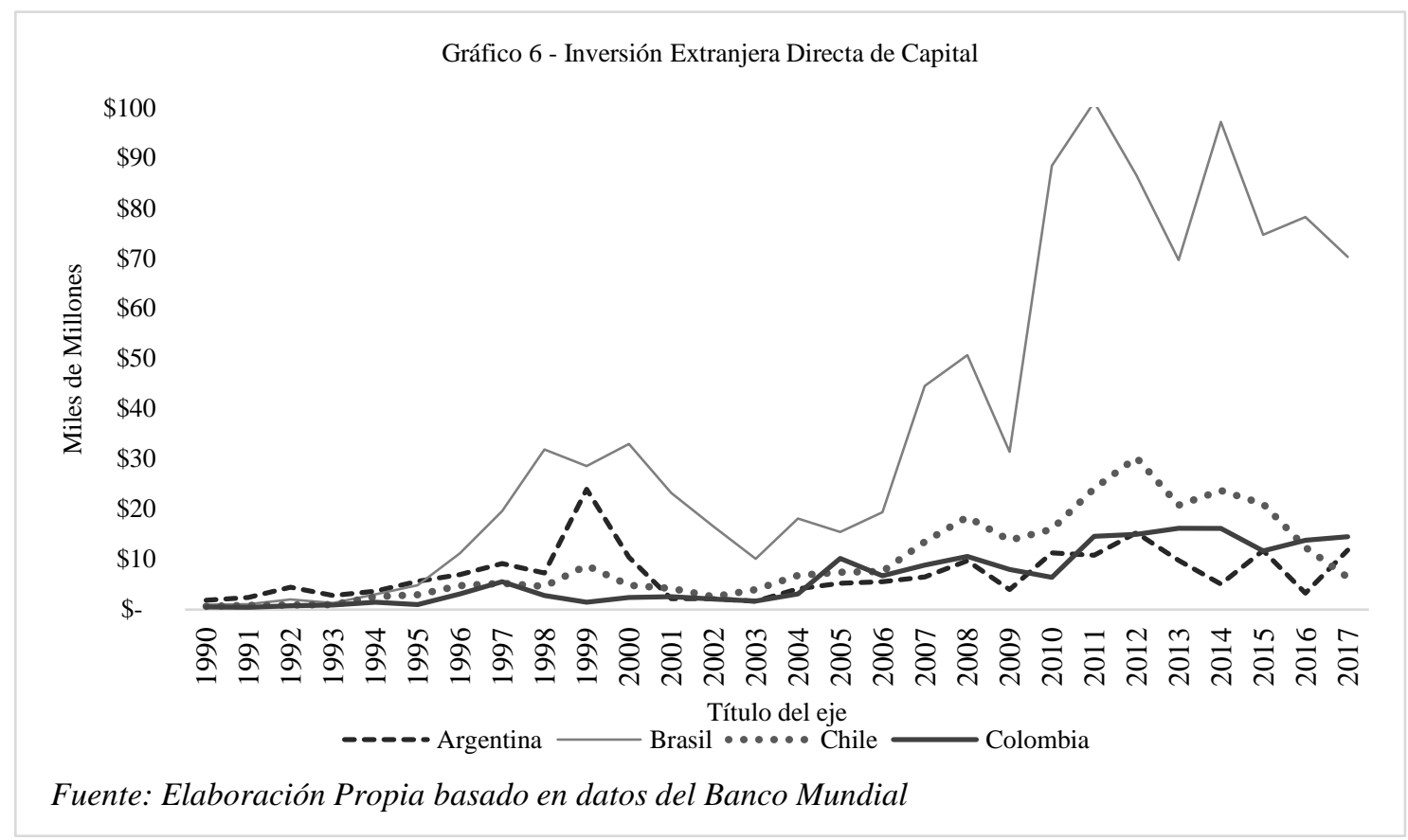

\section{$\underline{\text { Indicadores de Competitividad Global }}$}

Con respecto a los indicadores globales de Competitividad, el índice Doing Business del Banco Mundial (Ver tabla 2) arroja una luz sobre el estado de Chile en comparación con sus pares regionales, tres de los indicadores de este índice son relevantes si se quiere determinar el nivel de competitividad de Chile, por un lado, el indicador Apertura de un Negocio, que básicamente refleja que tan fácil es abrir un negocio en cuanto a normatividad y condiciones favorables para el emprendimiento, deja a Chile en el puesto 65 en un universo de 212 países, superando ampliamente a Argentina, Brasil, Colombia y Uruguay. 


\begin{tabular}{c|ccccc} 
Indicador / País & Argentina & Brasil & Chile & Colombia & Uruguay \\
Apertura de un negocio & 157 & 176 & 65 & 96 & 61 \\
$\begin{array}{c}\text { - Clasificación } \\
\text { Comercio }\end{array}$ & 116 & 139 & 68 & 125 & 151 \\
$\begin{array}{c}\text { transfronterizo }- \\
\text { Clasificación }\end{array}$ & 117 & 125 & 55 & 59 & 94 \\
$\begin{array}{c}\text { Facilidad de hacer } \\
\text { negocios }\end{array}$ & & & & &
\end{tabular}

Fuente: Elaboración Propia basado en el Índice del Banco Mundial Doing Business Tabla 2. Indice Dping Business

En esta materia el ejecutivo ha hecho esfuerzos como la creación en 2015 de una plataforma integrada de servicios públicos llamada Escritorio Empresa, en donde las empresas pueden realizar varios trámites e integrar 50 procedimientos con 18 entidades públicas y 114 municipios (OCDE, 2018), en línea con lo anterior, las reformas han posibilitado que el registro de sociedades sea más optimo con la creación de un portal digital para procedimientos empresariales (OCDE, 2018); el segundo indicador que es Comercio Transfronterizo Chile se encuentra en el puesto 68 y en este sentido, Chile no solo sobresale por su calificación, sino, por los esfuerzo realizados en materia de exportaciones y comercio exterior, consiguiendo vencer las barreas y dificultades de su accidentada geografía. El último indicador de gran relevancia para este análisis de competitividad es La Facilidad de Hacer Negocios, puesto que resume en su conjunto los demás indicadores del índice, aquí Chile ocupa el puesto 55, levemente superior que Colombia y muy por encima de Brasil y Argentina.

Otro grupo de indicadores que ilustra el estado actual de la economía chilena es el Índice de Competitividad Global del World Economic Forum, este índice como lo describe Riveros Cornejo \& Báez Castillo, (2014)

Reúne doce variables de análisis que el Foro Económico Mundial organiza en tres grupos. Un primer grupo es el relativo a los requisitos básicos, que comprende i) estabilidad macroeconómica, ii) calidad de las instituciones, iii) infraestructura social, y iv) provisión de educación primaria y salud. Un segundo grupo de factores que determinan la competitividad de la economía se refiere a aspectos como v) calidad de la educación superior, vi) eficiencia del mercado de bienes, vii) eficiencia del mercado del trabajo, viii) sofisticación del mercado financiero, ix) preparación tecnológica y x) tamaño de mercado. En último término, se adiciona un tercer grupo de variables que se relacionan con aquellos factores que potencian la innovación en una economía, a saber: xi) sofisticación de los negocios y por último xii) innovación. (p.14) 
Dentro de las variables que análiza, Chile ocupa el puesto $\mathrm{N}^{\circ} 66$ de 152 paises considerados en materia de confiabilidad en los servidores públicos, en aspectos como eficiencia del gasto gubernamental chile ocupa el puesto $\mathrm{N}^{\circ} 80$, y en el indicador de eficiencia del gobierno ocupa el puesto $\mathrm{N}^{\circ} 54$, en transparenciea en la formulación de políticas gubernamentales ocupa el puesto $\mathrm{N}^{\circ} 35$; en Infraestructura de transporte se encuentra en el puesto 29 y en entorno macronoeconómico en el lugar 36. Por último en el índice Global, Chile ocupa el puesto $\mathrm{N}^{\circ} 33$, por encima de Colombia que esta el $\mathrm{N}^{\circ} 66$, de Argentina que ocupa el 92 y Brasil que se encuentra en el puesto 80, como resultado de lo anerior, el Foro Economico Mundial resalta el desempeño de la economia chilena y la catalogó como la economía más competitiva de América Latina elogiando su crecimiento y solidez (Riveros Cornejo \& Báez Castillo, 2014).

Según los datos de La Organización Mundial del Comercio del año 2016, Chile se ubica en la venta de mercanicas en el puesto $\mathrm{N}^{\circ} 42$ en el nivel de exportación a nivel mundial, y en los servicos comerciales en el puesto 59 también en la línea de exportador a nivel mundial. En este sentido y en línea con lo que ya se ha enunciado, se estable que el ambiente de las variables economicas en su conjunto, así como la facilidad de creación de negocios resultan fundamentales para aportar a la competitidad de un páis (Riveros Cornejo \& Báez Castillo, 2014). Lo que nos lleva a afirmar que Chile esta por encima de sus pares regionales en competividad y capacidad de dinamizar su economía.

\section{Infraestructura}

En materia de infraestrutucra lógistica y servicos, Chile ha dado pasos importantes en la consolidación de la inversión en estos topicos. Desde 1993 se abrió el proceso de concesiones de obras de infraestructura, en donde el foco se centraba en la financión de obras publicas, cómo carreteras, puertos, aeropuertos,carceles y hospitales (Saavedra, 2014), en años recientes y con el objetivo de reforzar los fondos de financiamiento privado de nuevos proyectos, el congreso aprobó un nuevo fondo de infraestructura, lo que ha hecho posible el aumento de la inversión más de lo previsto, aportando también al incremento de la productividad y competitividad (OCDE, 2018).

Sin embargo, el índice de desempeño logístico: calidad de la infraestructura relacionada con el comercio y transporte del Banco Mundial indica que para el año 2016 Chile tuvo una calificaicón de 2,8 levemente por debajo de Brasil con 3,1 y Argentina 2,9, solamente superando a Colombia que obtuvo un 2,4. Aún así, en el índice de desempeñpo logístico total del Banco Mundial que refleja las percepciones de la logística de un país basadas en la eficiencia del proceso del despacho de aduana, la calidad de la infraestructura relacionada con el comercio y el transporte, la facilidad de acordar embarques a precios competitivos, la calidad de los servicios logísticos, la capacidad de seguir y rastrear los envíos, y la frecuencia con la cual los embarques llegan al consignatario en el tiempo programado (World Bank Group, 2018). El índice varía entre 1 y 5, donde el puntaje más alto representa un mejor desempeño, vemos que Chile obtuvo en el año 2016 una puntuación de 3,25 superando a Brasil que obtuvo 3,09, Argentina con 2,96 y a Colombia 
que punteo con 2,61, lo que indica que Chile ha mejorado su infraestructura en los últimos años, benficiandose de las inversiones en los ambitos público y público - privado (OCDE, 2018), no obstante, Chile supera apenas a sus pares regionales, lo cual sin duda, también resulta preocupante, ya que debe seguir mejorando sus sistemas de tranporte e infraestructura para mantener su posición de competidor de talla mundial.

\section{Apertura Económica}

Gráfico 7 - Principales mercados de exportación, excluida la minería

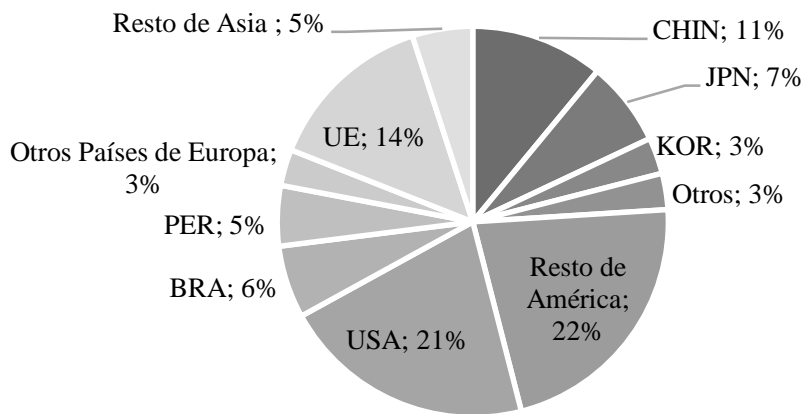

Fuente: OCDE 2018: Banco Central de Chile (2017), base de datos estadística

La apertura económica de Chile durante las décadas de 1970 y 1980 ofreció una plataforma de crecimiento económico y fortalecimiento de la competitividad de la economía. La tesis expuso que las ventajas comparativas de Chile aumentarían las exportaciones, el crecimiento y el desarrollo, ya que el sistema productivo interno tendría que introducir nuevas tecnologías e innovaciones para hacerle frente a la competencia internacional (Dingemans, 2016). Posteriormente, durante los años 90 los gobiernos de la concertación mantuvieron una política enfocada en los acuerdos de libre comercio gestionados con sus principales socios, Estados Unidos, Japón, La Unión Europea y China (Saavedra, 2014), destacando que se le atribuye por parte de las políticas económicas de Chile al sector externo, ser fuente de crecimiento económico (Dingemans, 2016).

Los resultados de la apertura económica se vieron reflejados durante los primeros años de implementación, en 1975 las exportaciones en dólares corrientes ascendían a 1.129 millones, para 1990 este valor llegó a ubicarse en 6.312 millones (Dingemans, 2016). En relación con lo anterior, la política pública ha hecho sus mayores esfuerzos en el fortalecimiento de asociaciones, institucionalidad y en la elaboración de tratados comerciales (Poblete \& Amorós, 2013); al día de hoy, Chile cuenta con 26 acuerdos comerciales vigentes (Gobierno de Chile, 2018), convirtiendo a Chile en uno de los países que más tratados de libre comercio tiene, alcanzando mercados a nivel mundial, como lo muestra el gráfico 7 , en donde se observa los diferentes mercados de mayor 
importancia para la económica chilena, resaltando el nivel de exportaciones hacía América Latina, Estados Unidos., China, La Unión Europea, Japón, Corea, entre otros.

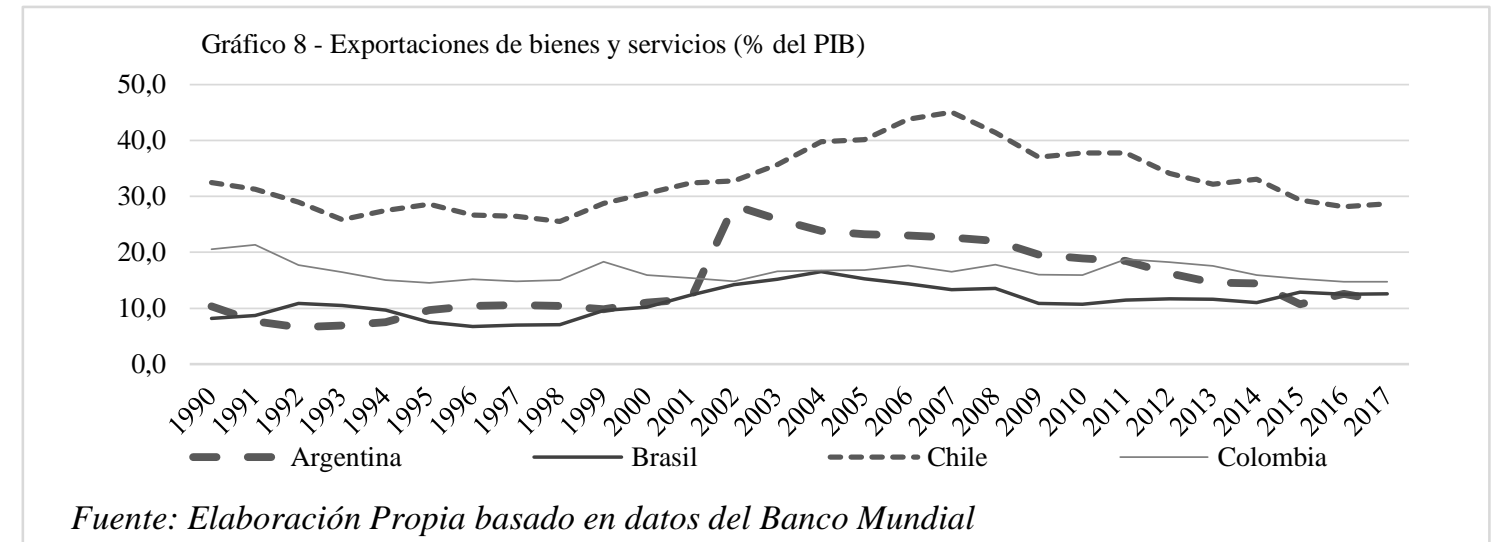

Los acuerdos internacionales han permitido a Chile dinamizar su aparato productivo aportando al crecimiento y adquiriendo un nivel de exportación mayor al de sus pares regionales. El gráfico 8 muestra las exportaciones de bienes y servicios como \% del PIB de Chile, Argentina, Brasil, y Colombia. Se destaca que el porcentaje de participación de las exportaciones dentro del PIB de Chile es ampliamente mayor que al de sus pares regionales concluyendo que el sector de exportaciones es clave para el desarrollo y crecimiento de la económica chilena.

El compromiso de los Gobiernos en mantener esfuerzos concentrados en reforzar su esquema base de exportaciones, viene tejiéndose desde entidades como Prochile, la cual ha sido un eje clave de la estrategia del ejecutivo, apoyando a los exportadores en servicios cómo, participación en conferencias de negocios, asesorías en mercadeo y desarrollo de rondas de negocios, concentrándose en empresas de sectores no tradicionales y en exportaciones diferentes al cobre y sus derivados (Dingemans, 2016), aumentando el nivel de exportaciones y desarrollando sectores como forestal, frutícola y vitivinícola, así como la industria del salmón (Dingemans, 2016). Aun así, como lo muestra el grafico 9, uno de los principales retos de la economía chilena será seguir haciendo esfuerzos para diversificar sus fuentes de exportación, debido a que el Cobre sigue siendo el producto que tiene mayor participación en la exportación total de chile con un $48 \%$ (OCDE, 2018). Lo anterior, indica que la económica chilena aún es muy dependiente del cobre; lo anterior, evidencia un reto enorme para desarrollar y 
diversificar la base productiva generando mayor diferencia de valor en los otros productos de exportación.

No obstante, la inmersión de Chile dentro del círculo internacional ha integrado al país dentro de una red mundial, incrementando sus opciones para impulsar la productividad y competitividad a la vez que facilita el intercambio comercial y la contribución en diversos ámbitos (Riveros Cornejo \& Báez Castillo, 2014).

\section{Educación, desarrollo inclusivo y desigualdad: los puntos álgidos del modelo económico de Chile.}

El desempeño de Chile en los indicadores macroeconómicos es admirable, alcanzando incluso resultados de países desarrollados, no obstante, en la medición de otros indicadores más básicos, Chile muestra un desempeño pobre alineándose como un país subdesarrollado (Riveros Cornejo \& Báez Castillo, 2014). En países de la OCDE, por ejemplo, se evidencia un nivel mayor de equidad y distribución del ingreso (Garcia S \& Pérez N, 2017). Si bien, la pobreza sea disminuido a través del mejoramiento de la protección social, el gasto público cómo porcentaje del PIB fue de apenas 1,8\% en 2015, en países de la OCDE este porcentaje no baja de 2,2\% del PIB (OCDE, 2018). De otro modo, Chile también presenta números rojos en materia de formación del capital humano básico (Riveros Cornejo \& Báez Castillo, 2014). Así mismo, la OCDE, (2018) resalta que la población adulta no cuenta con las competencias básicas requeridas, es decir, la educación superior no prepara adecuadamente a los estudiantes para un mercado laboral competitivo lo que denota en el aumento de la inequidad y desigualdad.

\section{Educación}

A efectos de las consideraciones hechas, se puede afirmar que parte de los grandes retos de Chile es aumentar la Calidad de su sistema educativo; sin embargo, como lo afirma la OCDE (2018), Chile no cuenta con un sistema nacional de aprendizaje que dé cumplimiento a unos objetivos previamente establecidos y a un marco regulatorio definido, lo que ha provocado desigualdad y falta de oportunidades equitativas en el acceso a la capacitación y aprendizaje, situación que ha contribuido al decrecimiento de la inclusión y la productividad.

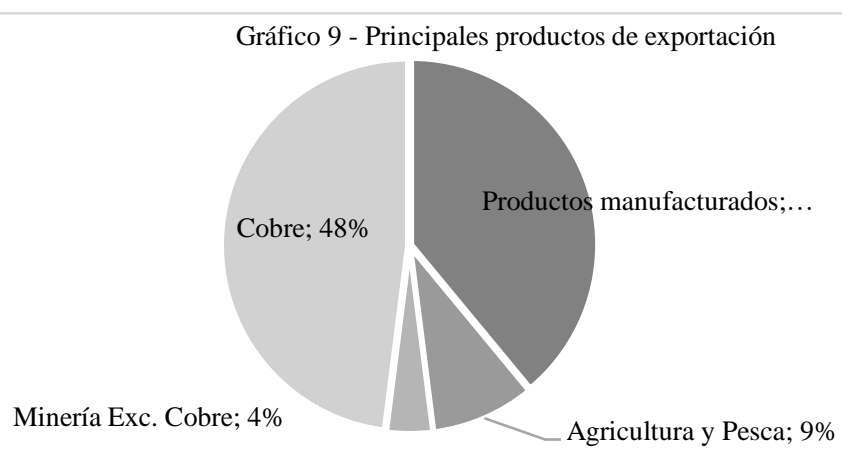

Fuente: OCDE 2018: Banco Central de Chile (2017), base de datos estadística 
El Índice de Competitividad Global del World Economic Forum del año 2018 en el indicador que mide la calidad del sistema educativo donde se califica de 1 a 7 en donde 7 es mejor y 1 peor, Chile obtiene una calificación apenas de 3,4 y lo ubica dentro del ranking en el puesto 86, superado ampliamente por Estados Unidos con 5,6, y equiparándose con el desempeño de sus pares regionales como Colombia y Uruguay con 3,4 aunque es superado por Argentina que obtiene 4,3.

En el gráfico 10 se muestra el porcentaje del gasto público en educación respecto al PIB, para el 2014, Chile apenas gasta el 4,2\% en educación, muy por debajo de países más desarrollados como Estados Unidos con $5.0 \%$ y considerablemente inferior de sus pares reales cómo de Brasil y Argentina con $5.4 \%$ y $5.9 \%$ respectivamente.

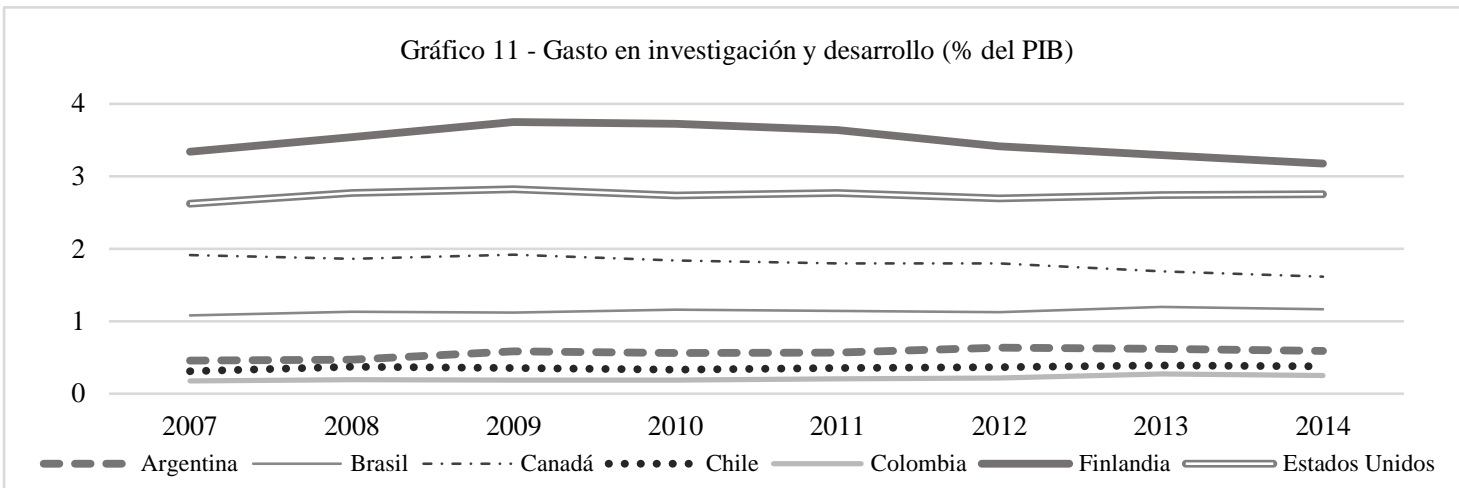

Fuente: Elaboración Propia basado en datos del Banco Mundial

Si bien es cierto que Chile se acerca al promedio de sus países vecinos, debe orientar esfuerzos en mejorar la calidad de su educación y aumentar el gasto público en el sistema de aprendizaje como herramienta para reducir las brechas existentes en la desigualdad del ingreso y construir caminos que lleven a un desarrollo más inclusivo, por otro lado, Chile tendría que adoptar reformas sociales centradas en la mujer y en los trabajadores con menores capacidades técnicas, como una estrategia para el desarrollo inclusivo (OCDE, 2018), sumado a otros grandes retos como la informalidad, el mejoramiento de la eficiencia del gasto social, y la generación de empleo de calidad garantizando también el acceso a la educación (OCDE, 2018). En este propósito Chile debe apegarse a sus fortalezas como sus políticas fiscales y manejo macroeconómico para solventar un crecimiento más inclusivo, pero al mismo tiempo, dando cumplimiento con los objeticos de crecimiento y las necesidades de una clase media en expansión que aporta de forma significativa al crecimiento económico (Wolrd Bank Group, 2018).

\section{Investigación y Desarrollo}

La investigación y desarrollo es fundamental para desarrollar nuevas capacidades tecnológicas y competitivas dentro de los sectores productivos de una economía, disminuyendo los costos operativos y de capital, también, es un insumo fundamental para producir nuevos productos y servicios que a través de la innovación generan valor en los 
mercados altamente competitivos. Sin embargo, es un componente importante como resultado de los procesos educativos de investigación en los diferentes campos técnicos. En el gráfico 11 se ve la inversión en I+D del 2007 al 2014 en donde el promedio de Chile es de 0,4\%, en comparación con Brasil 1,1\%, Estados Unidos 2,6\%, Finlandia3,2\%, Canadá 1,8\% y Argentina $0,5 \%$, Chile se ubica en una mala posición sólo superando a Colombia que presenta un promedio de $0,2 \%$ y se presenta muy lejos de países con un ingreso superior como Canadá, Finlandia y Estados Unidos.

Es por lo anterior, que Chile debe aumentar los recursos para invertir en esta materia, según la OCDE (2018), las empresas jóvenes y pequeñas no cuentan con los recursos suficientes para invertir en I+D y los créditos son demasiado costosos; lo que limita las posibilidades de casos de éxito. Dentro de las recomendaciones de la OCDE (2018), se destaca la implementación de evaluaciones con indicadores ex-post para medir los programas en los que el gobierno invierte los recursos de I+D y cuantificar su impacto económico, también se hace necesario emplear criterios de inversión en sectores estratégicos para la económica de Chile y la creación de una plataforma nacional que favorecería las medidas de apoyo para las empresas y brindaría fácil acceso a la información por parte de las mismas.

\section{Desigualdad}

Cómo ya hemos precisado antes, Chile ha gozado de un crecimiento económico destacado, sobresaliendo entre sus pares regionales, no obstante, como señala Mella Polanco \& Berrios Silva, (2013) "el modelo transicional chileno, gatillador de la redemocratización durante los años 90, ha demostrado carecer de flexibilidad y capacidad de adaptación a los nuevos contextos" (p437). "La sociedad chilena es percibida como una con altos niveles de desigualdad" (Gamboa \& Segovia, 2015,p.p) si se toma como referencia el coeficiente Gini de 0,516 en 2013 ubicándose apenas por encima del promedio regional, lo que convierte a Chile en uno de los países más desiguales de América Latina y de la OCDE (Arenas de Mesa, 2016).

La desigualdad en Chile se ha proyectado como un debate público después de las manifestaciones estudiantiles en los años 2006 y 2011 (Rodríguez Weber, 2014). Parte del problema fue la gestión de los gobiernos de la concertación que descuidaron la regulación de las tasas de ingreso, concentrando todo su esfuerzo en decrecer la pobreza (Gazmuri, 2012), factor que si bien es importante, no elimina el riesgo de una economía al crecer de forma importante pero con problemas estructurales de gran impacto social; en este sentido Espinoza, , Barozet, \& Méndez (2013) sostienen que la tasa de pobreza ha llegado a un techo estructural el cual la intervención del estado no puede resolver, aduciendo un problema estrcutural de una sociedad chilena desigual, en donde los más ricos concentran un gran porcentaje de la riqueza nacional.

Como concecuencia de lo anterior, la desigualdad en la distribución de los ingresos llevo a que el ingreso promedio del $20 \%$ de la población con ingresos superiores como múltiplo 
del ingreso promedio del $20 \%$ de la población con ingresos inferiores de la escala de ingresos, según las estadísticas de la OCDE, en el año 2013 se ubicara en 10,6 cuando el promedio de la OCDE es de 5,3. Esta situación como afirma Arenas de Mesa (2016) ha dado como resultado una efimera movilidad social y condiciones económicas precarias para varías generaciones, afectando directamente el crecimiento económico si se tiene en cuenta que mayores niveles de desigualdad representan crecimiento de los niveles de desestabilidad. Algunos de los orgienes de esta problemática, son como lo indicaron Espinoza, , Barozet, \& Méndez (2013) la privatización de las empresas del sector público, aportando así a los interereses de las grandes empresas y aumentando con ello la concentración de los recursos, constiyendose tal situación en fuente de desigualdad.

Aunque son diversos los factores que generan desigualdad en los ingresos, Garcia S \& Pérez N (2017) apuntan a que es preciso lograr estabilidad macrofinaniciera, evitando crisis inflacionarias o financieras y caidas de la economía, ya que esto conlleva a eviar afectaciones negativas en la equidad, sin embargo, es valido considerar que si el crecimiento económico está caracterizado por la extracción de recursos naturales, y esto a su vez conlleva una incompatibilidad con las competencias tecnologícas de población, es oportuno entonces, aprovechar el contexto actual para generar un cambio en el estilo de desarrollo (Rodríguez Weber, 2014). En el pasado el problema central era atacar la pobreza, no obstante, en la actualidad las politícas sociales deben ir enfocadas en frenar la desigualdad, de lo contrario, se seguirán creando barreras que obstaculicen el crecimiento sostenible, agudizando los problemas en la prestación de los servicios sociales más básicos y el acceso de los bienes primarios, impactando directamente la estabilidad socioeconomica de la nación (Arenas de Mesa, 2016). 


\section{Conclusiones}

Chile es una de las economías más competitivas de la región, con picos de crecimiento económico superiores al $6 \%$ durante la década de los años 90 , lo anterior, producto de las diferentes reformas estructurales que se llevaron a cabo los últimos 30 años, como por ejemplo las reformas tributarias de 1990 y 2014. Adicional, los esfuerzos realizados por los gobiernos en temas como la corrupción, transparencia y libre competencia, junto con un marco jurídico estable, blindan un ambiente de confianza empresarial que aporta un voto de confianza en pro del crecimiento económico. Por otro lado, se destaca el papel del Banco Central de Chile como un promotor del crecimiento económico, llevando su papel con compromiso admirable en lo que respecta a su gestión en la política monetaria y el cumplimiento de sus metas inflacionarias, corroborando que la independencia entre el ejecutivo y el emisor es una acertada medida para el bienestar de la política económica.

Los diferentes índices de competitividad revisados en este artículo, brindan una clara visión del perfil y potencial competitivo de Chile y de su infraestructura que aún tiene retos importantes en términos de adecuación a las necesidades de varios sistemas productivos, aun así, los resultados en logística y servicios posicionan al país austral en un sitio privilegiado para la conectividad, destacando aspectos como su facilidad para hacer negocios y su buen entorno empresarial, algo que para los inversionistas es criterio de peso para tomar decisiones sobre sus portafolios de inversiones.

Esta realidad, nace a partir de la apertura económica lograda en la década de los años 70 y consolidada en los siguientes 20 años, a la fecha Chile es reconocido por sus negociaciones en tratados de libre comercio y con 26 tratados vigentes refuerza sus ventajas competitivas alcanzando mercados en casi todo el globo. Sin embargo, también representa uno de los mayores retos para su economía, ya que el mayor ingreso por exportaciones sigue siendo el Cobre y la extracción de otros recursos naturales, es así, que se presenta un desafío aún mayor en cuanto a la diversificación de la base exportadora. Para lograrlo, se deberá mejorar aspectos como la calidad en la educación y competencias básicas de la población activa, esto, junto con un aumento de los recursos e iniciativas de apoyo para fomentar la investigación y el desarrollo dentro de las empresas, logrará desarrollar nuevas tecnologías e innovaciones que le permitirá expandir y diversificar sus bases de exportación, ampliar su oferta de valor, y reforzar su posición competitiva en industrias como la forestal, frutícola, vitivinícola y el salmón, en las cuales hoy día Chile se presenta como un referente.

En otro sentido, y quizá más importante aún, será reducir los altos niveles de desigualdad e inequidad, temas que se convirtieron hasta el año 2013 después de las elecciones presidenciales, en aspectos principales de la agenda política nacional (Gamboa \& Segovia, 2015). Es importante medir constantemente todos los esfuerzos que realiza Chile, contra los principales indicadores de pobreza y desigualdad como el índice Gini, 
adicional, es fundamental dimensionar la problemática de la desigualdad a partir de ejercicios como el desarrollado por Garcia S \& Pérez N (2017) en el cual se define qué:

La unidad de análisis tradicional para estudiar la desigualdad económica de una sociedad es el hogar, debido a que las decisiones de consumo se toman al interior de este y están condicionadas por su composición demográfica y su estructura social. Con el objeto de llevar a cabo comparaciones coherentes de las variaciones en la desigualdad de los ingresos, se construyeron dos medidas de ingresos. La primera es el Ingreso Total del Hogar, que corresponde a la suma de los ingresos totales de todos los miembros del hogar. La segunda medida es el Ingreso Per Cápita, el que muestra cómo se divide el Ingreso Total del Hogar por el número de integrantes que dependen de dichos ingresos (p 191-192).

Los resultados de este tabajo arrojanron que en los hogares de menor ingresos, existe un mayor número de personas, por el contrario, en hogares con mayores ingresos, existe un menor número de personas, lo que indica brechas importantes en la desigualdad de ingresos, adicional, también concluyen que el 10\% de las personas que registran mayores ingresos, tienen el $40 \%$ de la participación en los ingresos totales. El 5\% de mayores ingresos obtiene una participación del $27 \%$ de todos los ingresos totales.

A partir de lo expuesto, se propone mejorar las políticas de distribución de recursos, mejorar significativamente el sistema educativo con el principal objetivo de brindar una educación de mayor calidad, garantizando el alcance de la misma a la población de menor ingreso; en paralelo, se debe profundizar el enfoque de las reformas estructurales que permitan generar nuevas fuentes de crecimiento. Si bien, las fuentes de crecimiento no garantizan que la desigualdad se reduzca por completo, sí aporta en la genereación de nuevas oportunidades para la población de menor ingreso y poblacion que cuenta con algun riesgo de vulnerabilidad, y brinda, junto con las habilidades y capacidades adquiridas producto de una educacion de calidad y de reformas en el sismta nacional de aprendizaje que oriente sus estrategias a subsanar las dificultades en la capacitación y aprendizaje de la población activa, los medios necesarios para mejorar el acceso a empleo de calidad, el cual como cita la OCDE (2018) "puede aumentar el bienestar y promover la productividad al tiempo que reduce las desigualdades en el mercado de trabajo"(p36). También "las reformas relacionadas con la protección del empleo deben ir acompañadas de una red de protección social más eficaz así como de unas políticas de capacitación e intermediación más eficientes" (OCDE,2018,p39). Además, es necesario enfocar la política fiscal para garantizar la financiación de proyectos con iniciativas sociales para aumentar el desarrollo inclusivo, en esta línea, se hace necesario una nueva reforma tributaria, que como lo señala la OCDE (2018) permitirá "el aumento del gasto social que requerirá que se continúe con la reforma del sistema tributario para incrementar los ingresos y mejorar el crecimiento y la equidad en el mediano plazo" (p.33).

Por último, "los desafíos existentes para conseguir un crecimiento más inclusivo dependerán de reducir la informalidad, mejorar el gasto social y crear oportunidades de 
empleo de alta calidad en el mercado de trabajo y a través de la educación" (OCDE,2018,p27). No obstante, como lo plantea Rodríguez, Weber (2014), vale la pena comenzar una discusión en torno al modelo de crecimiento actual, para lograr un estilo de desarrollo diferente, más equitativo y menos desigual como el actual. 


\section{Referencias}

Arenas de Mesa, A. (2016). Sostenibilidad Fiscal y Reformas Tributarias en Améria Latina. Santiago: Comisión Económica para América Latina y el Caribe (CEPAL).

De Gregorio, J. (2009). A Veinte años de la Autonomía del Banco Central de Chile. Economía Chilena, 12(3), 5-10.

Dingemans, A. (2016). El Fin de una Etapa Exitosa Los TLC en la Estrategia Comercial de Chile. Revista de Economía Institucional, 18(34), 151-172.

Espinoza, , V., Barozet, E., \& Méndez, M. (2013). Estratificación y Movilidad Social bajo un Modelo Neoliberal: El caso de Chile. Revista Lavboratorio(25), 169-191.

Fairfield, T. (2015). LA ECONOMÍA POLÍTICA DE LA REFORMA TRIBUTARIA PROGRESIVA EN CHILE. Revista de Economía Institucional, 17(32), 129-156.

Ffrench Davis, R. (2016). PROGRESOS Y RETROCESOS DEL DESARROLLO ECONÓMICO DE CHILE EN LOS. El Trimestre Económico, LXXXIII (1)(329), 5-34.

Gamboa, R., \& Segovia, C. (2015). Imágenes de desigualdad en Chile: El impacto de factores económicos y políticos. Papel Político, 20(2), a-t.

García - Solanes , J., \& Torrejón - Flores, F. (2012). La fijación de metas de inflación da buenos resultados en América Latina. Revista CEPAL, 106, 37-55.

Garcia S, P., \& Pérez N, C. (2017). Desigualdad, inflación, ciclos y crisis en Chile. Estudios de Economía, 44(2), 185-221.

Gazmuri, C. (2012). Historia de Chile 1891-1994- Política, Economía, Sociedad, Cultura, Vida Privada, Episodios. Santiago : Rileditores.

Gobierno de Chile. (2018). Dirección General de Relaciones Económicas Internacionales. Obtenido de https://www.direcon.gob.cl/acuerdos-comerciales/

Larrañaga, O., \& Valenzuela, J. P. (2011). Estabilidad en la desigualdad. Chile 19902003. Estudios de Economía, 38(1), 295-329.

Mella Polanco, M., \& Berrios Silva, C. (2013). Gobernabilidad, democratización y conflictividad social en Chile: escenarios posibles para un nuevo equilibrio. Polis, Revista Latinoamericana, 12(35), 429-458.

Mujica , P., \& Saenz, R. (2015). Traspaso de tipo de cambio y metas de inflación en Chile. . Revista CEPAL, 117, 145-155.

Nuñez Salazar, I. M. (2015). Imaginarios culturales del cuidado en Chile. Trabajo y economía en larga duración. Polis, Revista Latinoamericana., 14(41), 461-479.

OCDE. (2018). Estudios Económicos de la OCDE Chile. Santiago: OECD Pusblishing.

OCDE. (2018). Organización para la Cooperación y el Desarrollo Económicos OCDE. Obtenido de Estadísticas OCDE: https://www.oecd.org/centrodemexico/estadisticas/

OCDE, CAF, \& CEPAL. (2018). Perspectivas económicas paa América Latina 2018 Repensando las Instituciones para el Desarrollo. Paris: Editions OCDE. Obtenido de https://repositorio.cepal.org/bitstream/handle/11362/43513/1/LEO2018_es.pdf 
Poblete, C., \& Amorós, J. (2013). Determninantes en la Estrategia de Internacionalización para las Pýmes: El Caso de Chile. Journal of Technology Management \& Innovation, 8(1), 97-106.

Riveros Cornejo, L., \& Báez Castillo, G. (2014). Chile y la OCDE. La dicotomia entre lo macroeconómico y el desarrollo humano. Estudios Inernacionales, 177, 9-34.

Rodríguez Weber, J. E. (2014). La Economía Política de la Desigualdad de Ingreso en Chile, 1850-2009. (Tesis doctoral). Universidad de la República - Facultad de Ciencias Sociales - Programa de Historia Económica y Social, Montevideo, Uruguay. Obtenido de http://cienciassociales.edu.uy/wpcontent/uploads/sites/6/2015/04/Rodr\%C3\%ADguez-Weber-Tesis-FinalPaginada.pdf

Saavedra, P. E. (2014). El Modelo Económico-Político de Chile: Desarrollo Institucional en la Encrucijada. Econmía y Política, 115-146.

Transparency International. (2017). Transparency International España. Obtenido de https://transparencia.org.es/wp-content/uploads/2018/02/tabla_sintetica_ipc2017.pdf

Wolrd Bank. (2017). Worldwide Governance Indicators. Obtenido de http://info.worldbank.org/governance/wgi/index.aspx\#home

Wolrd Bank Group. (2018). Chile Panorama General. Obtenido de http://www.bancomundial.org/es/country/chile/overview\#1

World Bank Group. (2018). Datos de libre acceso del Banco Mundial. Obtenido de https://datos.bancomundial.org/

World Bnak Group . (2018). Doing Business. Obtenido de http://espanol.doingbusiness.org/reports/global-reports/doing-business-2018

World Economic Forum . (2018). The Global Competitiveness Index 2017-2018 edition Argentina. Obtenido de http://www3.weforum.org/docs/GCR20172018/03CountryProfiles/Standalone2pagerprofiles/WEF_GCI_2017_2018_Profile_Argentina.pdf

World Economic Forum . (2018). The Global Competitiveness Index 2017-2018 edition Brazil . Obtenido de http://www3.weforum.org/docs/GCR20172018/03CountryProfiles/Standalone2pagerprofiles/WEF_GCI_2017_2018_Profile_Brazil.pdf

World Economic Forum . (2018). The Global Competitiveness Index 2017-2018 edition Chile. Obtenido de http://www3.weforum.org/docs/GCR20172018/03CountryProfiles/Standalone2pagerprofiles/WEF_GCI_2017_2018_Profile_Chile.pdf

World Economic Forum . (2018). The Global Competitiveness Index 2017-2018 edition Colombia. Obtenido de http://www3.weforum.org/docs/GCR20172018/03CountryProfiles/Standalone2pagerprofiles/WEF_GCI_2017_2018_Profile_Colombia.pdf

World Economic Forum. (2018). The Global Competitiveness Report 2017-2018. Obtenido de http://reports.weforum.org/global-competitiveness-index-20172018/\#topic=data 
